Research Article

\title{
The role of losartan and enalapril in the protection against stress-induced gastric mucosal ulceration in rats
}

\author{
Sanaa A. Ahmed ${ }^{1}$, Mahmoud H. Abdel-Rahim ${ }^{2}$, Hytham M. Abdel-latif ${ }^{1}$
}

\begin{abstract}
Received: 03 April 2016
Revised: 11 May 2016

Accepted: 12 May 2016

*Correspondence to:

Dr. Sanaa A. Ahmed,

Email: omran_sanaa

@yahoo.com
\end{abstract}

${ }^{1}$ Department of Pharmacology, Sohag University, Sohag, Egypt ${ }^{2}$ Department of Pharmacology, Assiut University, Assiut, Egypt

Copyright: (C) the author(s), publisher and licensee Medip Academy. This is an openaccess article distributed under the terms of the Creative Commons Attribution NonCommercial License, which permits unrestricted noncommercial use, distribution, and reproduction in any medium, provided the original work is properly cited.

\begin{abstract}
Background: Angiotensin II (ANG II) is a stress hormone and its level dramatically increases in the stomach during stress. In addition, it generates reactive oxygen species (ROS) with cellular damage and inflammation. So the aim of this study is to evaluate the mechanism of losartan and enalapril in the prevention of stress-induced gastric ulcer through their action on mucosal prostaglandin (PGs) and antioxidant enzymes and compare between them.

Methods: Thirty- six adult male wistar albino rats weighing 180-200 g were divided into 6 groups; $n=6$. Groups 1,2 , and 3 were received saline (normal control), losartan (3 mg/kg/day) and enalapril (10 mg/kg/day) i.p respectively for 4 weeks. Groups 4, 5, and 6 were pretreated with saline (ulcer control), losartan (3 mg/kg/day) and enalapril (10 mg/kg/day) i.p respectively for 4 weeks duration. On $29^{\text {th }}$ day, group 4, 5 and 6 were submitted to gastric ulcer by water immersion method, then animals of all groups were sacrificed, stomachs were excised for gross and microscopic examination and determination of the mucosal levels of prostaglandin E2 (PGE2), superoxide dismutase (SOD), nitric oxide (NO) and catalase (CAT).

Results: Stress produced gastric ulcer and a significant decrease in all measured gastric parameters compared to normal control group. Pre-treatment of rats with losartan or enalapril decreased the stress-induced alterations in mucosal parameters, but only losartan caused a significant increase in CAT activity in addition.

Conclusions: Antagonize the action of ANG II by losartan and enalapril have preventive advantages in stress-induced gastric ulcer and losartan has better influence as it has an additional effect on CAT activity.
\end{abstract}

Keywords: Losartan, Enalapril, Gastric ulcer, PGE2, SOD, Nitric oxide, Catalase

\section{INTRODUCTION}

A Peptic ulcer is the most common GIT disorder in the present day life of the industrialized and civilized world affecting $5-10 \%$ of the human population with etiology depending on the regional and socioeconomic factors but the pathogenesis of this disorder still remains little recognized. ${ }^{1}$ Pathophysiology of ulcer is due to an imbalance between aggressive factors (acid, pepsin, and Helicobacter infection) and local mucosal defensive factors (mucus, bicarbonate, and PGs). The integrity of gastro-duodenal mucosa is maintained through a homeostatic balance between these aggressive and defensive factors and nitric oxide, as well mucosal blood flow. ${ }^{2,3}$ Stress reduces gastric blood flow and produces acute gastric mucosal lesions. ${ }^{4}$ Angiotensin II (ANG II) is a stress hormone where the levels of which dramatically increase in plasma and tissues, including stomach, during stress. ${ }^{5}$ It is the main effector of the RAS where it is generated from the precursor angiotensinogen by the actions of renin, ACE, chymase and various peptidases. ${ }^{6}$ ANG II not only regulates vascular tone in resistance arteries and in the brain but also constricts the gastric vasculature through AT1R stimulation. ${ }^{7}$ In addition, ANG II generates reactive oxygen species (ROS) with cellular damage and inflammation. ${ }^{8}$ Oxidative stress with the generation of ROS, mucosal vasoconstriction and proinflammatory effects of ANG II could contribute to the production of stress-induced gastric ulcers. ${ }^{9}$

Possible association between peptic ulcer and ACEls and ARBs through their effects on ANG II is proved but their 
involvement in the mechanism of the protection of gastric mucosa has not been extensively studied. ${ }^{10}$

The aims of this study are to determine the protection afforded by losartan (as one of the ARBs) and enalapril (as one of the ACEIs) against stress-induced gastric mucosal damage in rats through their effects on the levels of PGE2, SOD, NO and CAT and to compare the efficacy of both drugs.

\section{METHODS}

\section{Materials}

Losartan potassium salt powder, enalapril maleate salt powder and kits for determination of PGE2 level by enzyme-linked immune-sorbent assay (ELISA) were obtained from Sigma-Aldrich (USA). Kits for determination of antioxidant parameters: (SOD, NO, CAT) were obtained from a Bio diagnostic company, Egypt.

\section{Animals}

Thirty-six male adult wistar rats weighing 180-200 g have been used. Animals were purchased from the animal house, Faculty of Medicine, Assiut University Egypt. The animals were kept at standard housing place, with room temperature being maintained at $22-24^{0} \mathrm{C}$. They were fed on a commercial pellet diet and kept under 12 hours light/dark cycle. Animals were given a free access to food and water. The experimental protocol was approved by the institutional animal care and use committee of faculty of medicine Sohag University, Egypt.

\section{Experimental protocol}

Induction of peptic ulcer by water immersion-restraint stress

Rats were starved for 24 hours but were allowed free access to water except for the last hour before the induction of ulcer by water-immersion method. They were stressed by wrapping them with iron net and then immersing them vertically to the level of xiphoid process in a water bath maintained at $20^{\circ} \mathrm{C}$ for 90 minutes. ${ }^{11}$

\section{Treatment}

Rats were randomly divided into 6 groups, 6 animals each. Group1, 2 and 3 were treated with $2 \mathrm{ml} / \mathrm{kg} /$ day saline i.p (normal control group), $3 \mathrm{mg} / \mathrm{kg} /$ day losartan i.p. dissolved in saline and $10 \mathrm{mg} / \mathrm{kg} / \mathrm{day}$ enalapril i.p dissolved in saline respectively. ${ }^{12,13}$ The duration of treatment was 4 weeks. Group 4, 5 and 6 were pretreated with $2 \mathrm{ml} / \mathrm{kg} /$ day saline i.p. (ulcer control group), 3 $\mathrm{mg} / \mathrm{kg} /$ day losartan i.p. and $10 \mathrm{mg} / \mathrm{kg} /$ day enalapril i.p. respectively. The duration of pre-treatment was 4 weeks. On $29^{\text {th }}$ day, after 24 hours of starvation, the animals of groups 4, 5, 6 were submitted to the gastric ulcer which was induced by stress as the previously described method between 9:00 AM and 12:00 PM. to avoid variations due to diurnal rhythms of putative regulators of gastric functions. Immediately after the end of the restraining period, the animals of all groups were killed by decapitation under light ether anaesthesia.

\section{Samples collection}

Immediately after decapitation, the animals of all groups were dissected. The stomachs were removed and opened along the greater curvature; the lumen was rinsed with saline. The stomach tissues were divided into two parts and weighted. First part at which gastric mucosa scrapped, homogenized in $2 \mathrm{ml}$ normal saline containing $0.1 \mathrm{M}$ dithiothreitol, for determination of PGE2 level in gastric tissues, the second part was homogenized in $2 \mathrm{ml}$ cold potassium phosphate buffer $(0.05 \mathrm{M}, \mathrm{pH} 7.4)$ for measurement of SOD and CAT enzyme activities and NO level. All samples were centrifuged at $2000 \mathrm{rpm}$ for 10 $\min$ at $4^{\circ} \mathrm{C}$. The supernatant was kept at $-80^{\circ} \mathrm{C}$ for subsequent measurement.

\section{Biochemical analysis}

\section{Determination of gastric prostaglandin E2 (PGE2)}

This assay employed the competitive inhibition enzyme immunoassay technique. The microtiter plate provided in this kit has been pre-coated with a goat-anti-rabbit antibody. Standards or samples are added to the appropriate microtiter plate wells with an antibody specific for PGE2 and Horseradish Peroxidase (HRP) conjugated PGE2 and incubated, then substrate solutions are added to each well. The reaction is terminated by the addition of a sulphuric acid solution and the colour change is measured spectrophotometrically at a wavelength of $450 \mathrm{~nm}^{14}$

Determination of gastric superoxide dismutase (SOD) enzymes activities

Activity of SOD in gastric tissue homogenate was determined by a colorimetric method using commercially available kits. The method was described by Nishikimi et al. ${ }^{15}$ This assay relies on the ability of the enzyme to inhibit the phenazine methosulphate-mediated reduction of nitroblue tetrazolium (NBT) dye. The change in the absorbance was measured at $560 \mathrm{~nm}$ for control and sample at $25^{\circ} \mathrm{C}$. SOD activity was expressed in $\mathrm{U} / \mathrm{g}$ tissues.

\section{Determination of gastric catalase (CAT) enzymes activities}

The enzyme activity was determined by a colorimetric method using commercially available kits, as described by Aebi. ${ }^{16}$ This assay relies on the reaction of CAT with a known quantity of $\mathrm{H} 2 \mathrm{O} 2$. The reaction is stopped after exactly one minute with CAT inhibitor. In the presence of peroxidase, the remaining $\mathrm{H} 2 \mathrm{O} 2$ reacts with 3 , 5dichloro-2-hydroxybenzene sulfonic acid (DHBS) and 4- 
amino-phenazone (AAP) to form a chromophore. The change in the absorbance was measured at $510 \mathrm{~nm}$. CAT activity was expressed in $\mathrm{U} / \mathrm{g}$ tissues.

\section{Determination of gastric nitric oxide (NO) level}

The level of NO was determined by a colorimetric method using commercially available kits according to the method of Montgomery and Dymock. ${ }^{17}$ This assay depends on that, in acid medium and in the presence of nitrite the formed nitrous acid diazotize sulphanilamide the product is coupled with $\mathrm{N}$-(1-naphthyl) ethylenediamine. The resulting azo dye has a bright reddish- purple colour which can be measured at $540 \mathrm{~nm}$. The level of NO was expressed in $\mathrm{nmol} / \mathrm{g}$ tissue.

\section{Histopathological examination}

Specimens of the stomach were examined macroscopically for the presence of gross changes, photographed by a digital camera (Fujifilm A100 China). Gastric tissue samples were fixed in $10 \%$ formalin, embedded in paraffin wax, sectioned and stained with hematoxylin and eosin for histopathological examination using light microscopy.

\section{Statistical analysis}

Data are expressed as mean \pm SEM, with a value of $\mathrm{P}<0.05$ considered statistically significant. Statistical evaluation was performed by one-way analysis of variance (ANOVA) followed by post hoc Tukey test for multiple comparisons of means. All analysis was performed with SPSS software package (version 17).

\section{RESULTS}

Effect of losartan and enalapril on gastric mucosa and on the levels of gastric mucosal PGE2, SOD, CAT and NO in male albino rats

After i.p administration of losartan in a dose of 3 $\mathrm{mg} / \mathrm{kg} /$ day and enalapril in a dose of $10 \mathrm{mg} / \mathrm{kg} /$ day for 4 weeks duration to rats, the mean PGE2 concentrations were significantly increased $(\mathrm{P}<0.05)$ from control level, $310 \pm 4.96$ to $330 \pm 7.09$ and $325 \pm 5.23$ respectively (Figure 1). Also, i.p injection of both losartan, and enalapril, in a same doses, route and duration as the previous test, produces significant increase $(\mathrm{P}<0.05)$ in gastric mucosal activity of SOD from $1.93 \pm 0.03$ to $2.11 \pm 0.03$ and $2.09 \pm 0.01$ respectively and increase in the mean of NO levels from $170 \pm 1.16$ to $195 \pm 2.89$ and $190 \pm 4.66$ respectively (Figure 2 and 4). On the other hand, only losartan led to a significant increase $(\mathrm{P}<0.05)$ in the gastric mucosal activity of CAT from $4.93 \pm 0.03$ to $5.15 \pm 0.03$ but enalapril led to insignificant changes in this enzyme activity compared to control group (Figure 3). The macroscopic picture showed that losartan and enalapril produced no pathological changes in gastric mucosa and the incidence of ulceration was zero\% (Table 1 and Figure 5, 6, and 7).

Table 1: Effect of pre-treatment with losartan (3 mg/kg/day) or enalapril (10 mg/ $\mathrm{kg} / \mathrm{day})$ i.p for 4 weeks duration on the incidence of stress-induced gastric ulceration (gross picture) in rats.

\begin{tabular}{|ll|}
\hline Groups & Incidence of ulceration (Gross picture) \\
\hline Control & $(0 / 6) 0 \%$ \\
\hline Losartan & $(0 / 6) 0 \%$ \\
\hline Enalapril & $(0 / 6) 0 \%$ \\
\hline Stress & $(4 / 6) 67 \%$ \\
\hline Losartan+stress & $(2 / 6) 33 \%$ \\
\hline Enalapril+stress & $(2 / 6) 33 \%$ \\
\hline
\end{tabular}

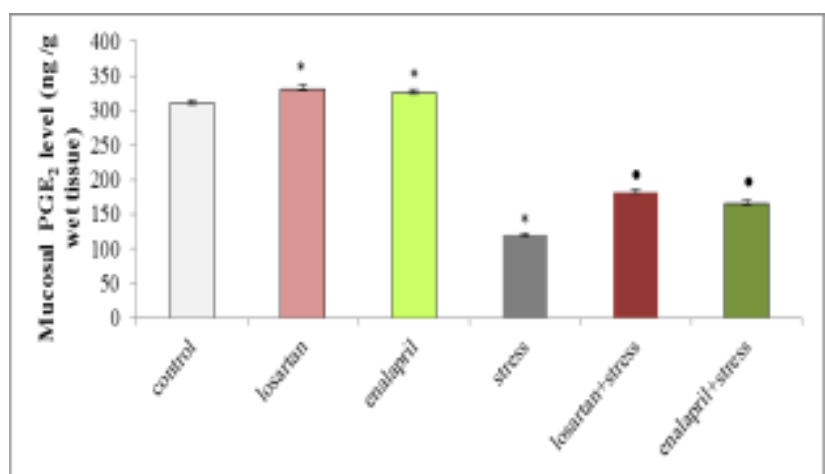

* Significant difference at $\mathrm{P}<0.05$ versus control group values.

- Significant difference at $\mathrm{P}<0.05$ versus stress group values.

Figure 1: Effect of i.p. injection of losartan (3 mg/kg/day) and enalapril (10 mg/kg/day) for 4 weeks duration on mucosal prostaglandin E2 (PGE2) level (ng/g wet tissue) in stress-induced gastric ulcer in rats.

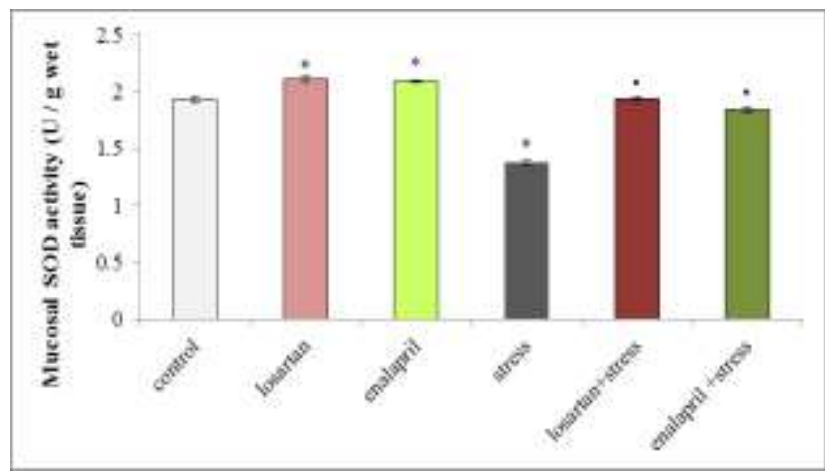

* Significant difference at $\mathrm{P}<0.05$ versus control group values.

- Significant difference at $\mathrm{P}<0.05$ versus stress group values.

Figure 2: Effect of i.p. injection of losartan (3 mg/kg/day) and enalapril (10 mg/kg/day) for 4 weeks duration on mucosal superoxide dismutase (SOD) activity (U/g wet tissue) in stress-induced gastric ulcer in rats. 
Effect of stress on gastric mucosa and on the levels of gastric mucosal PGE2, SOD, CAT and NO in male albino rats

Exposure of animals to stress led to significant reduction $(\mathrm{p}<0.05)$ not only in gastric mucosal PGE2 content from $310 \pm 4.96$ to $119 \pm 3.58$ and in gastric mucosal activity of SOD from $1.93 \pm 0.03$ to $1.38 \pm 0.02$ but also in CAT activity from $4.93 \pm 0.03$ to $3.14 \pm 0.03$ and in gastric NO from $170 \pm 1.16$ to $85 \pm 2.88$ all compared to control group, (Figures 1, 2, 3 and 4). The macroscopic picture showed that stress exposure produced ulceration and areas of severe inflammation in gastric mucosa and the incidence of ulceration was increased to reach $67 \%$ compared to control group (Table 1 and Figure 8).

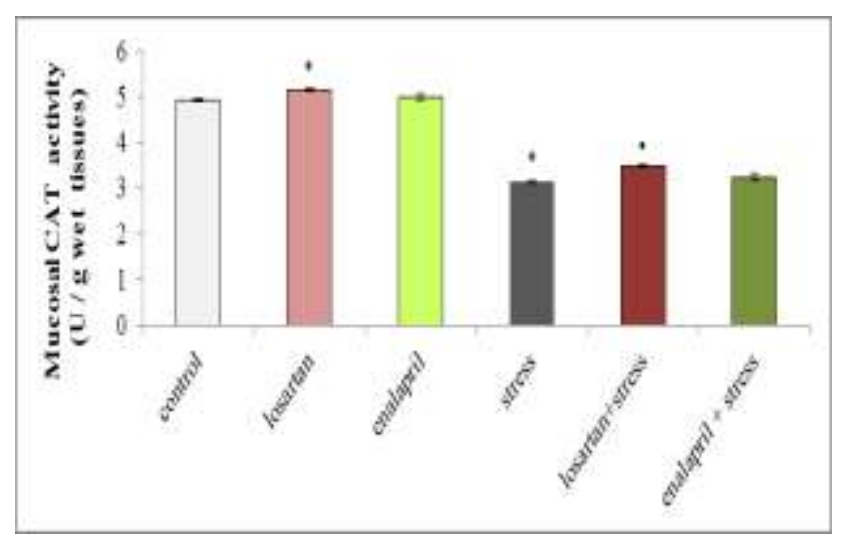

* Significant difference at $\mathrm{P}<0.05$ versus control group values.

- Significant difference at $\mathrm{P}<0.05$ versus stress group values.

Figure 3: Effect of i.p. injection of losartan (3 mg/kg/day) and enalapril (10 mg/kg/day) for 4 weeks duration on mucosal catalase (CAT) activity (U/g wet tissue) in stress-induced gastric ulcer in rats.

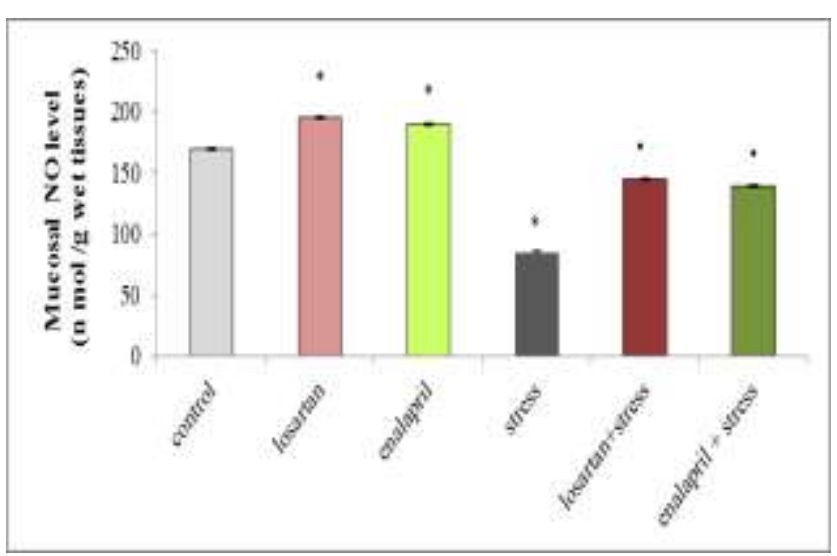

* Significant difference at $\mathrm{P}<0.05$ versus control group values.

- Significant difference at $\mathrm{P}<0.05$ versus stress group values.

Figure 4: Effect of i.p. injection of losartan ( $3 \mathrm{mg} / \mathrm{kg} / \mathrm{day})$ and enalapril (10 $\mathrm{mg} / \mathrm{kg} /$ day) for 4 weeks duration on mucosal nitric oxide (NO) level (nmol/g wet tissue) in stress- induced gastric ulcer in rats.

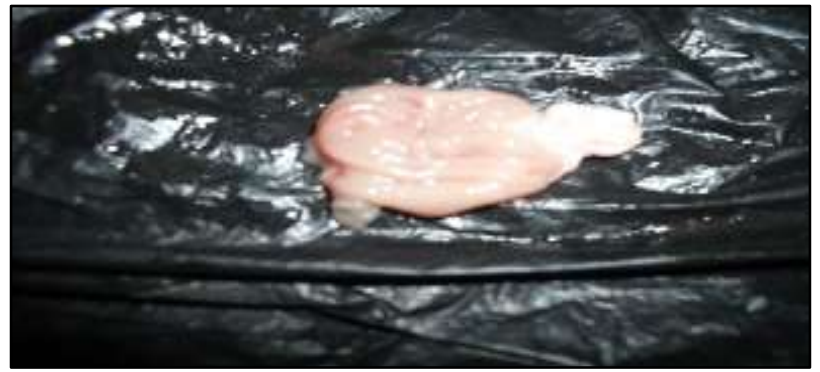

Figure 5: Gastric mucosa of rat from control group showing smooth gastric mucosa with no inflammation. The incidence of ulceration was zero \%.

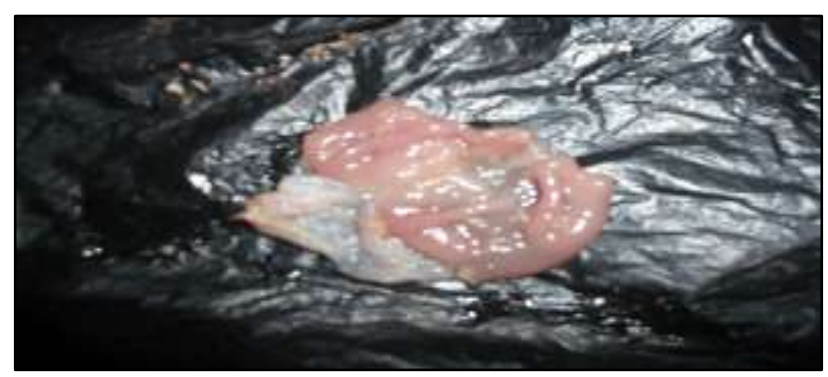

Figure 6: Gastric mucosa from rat received losartan for 4 weeks duration showing smooth gastric mucosa with no inflammation. The incidence of ulceration was zero\%.

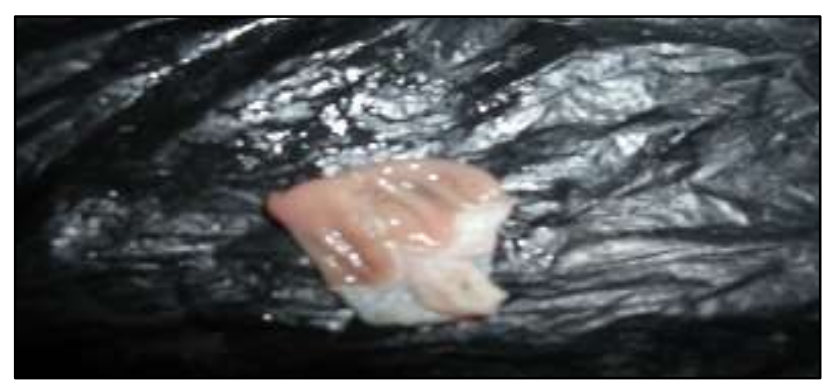

Figure 7: Gastric mucosa of rat received enalapril for 4 weeks duration, smooth gastric mucosa with no inflammation. The incidence of ulceration was zero\%.

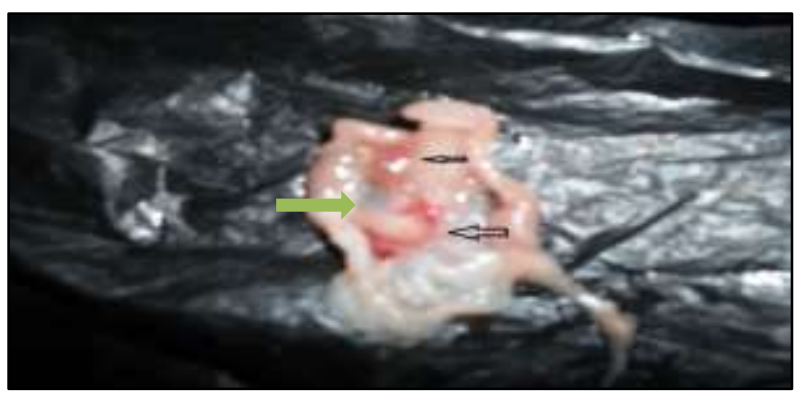

Figure 8: Gastric mucosa of stress-induced ulcer rat showing ulcers which appear with variable sizes (thick arrows) and areas of inflammation (thin arrow), the incidence of ulceration was $67 \%$. 


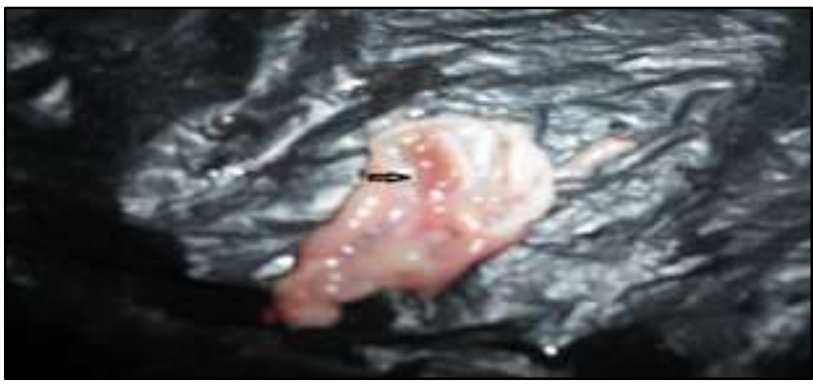

Figure 9: Gastric mucosa of rat pre-treated with losartan $3 \mathrm{mg} / \mathrm{kg} /$ day for 4 weeks duration before induction of ulcer by stress showing a decrease in the severity of inflammation areas with decrease in the incidence of ulceration to become $33 \%$.

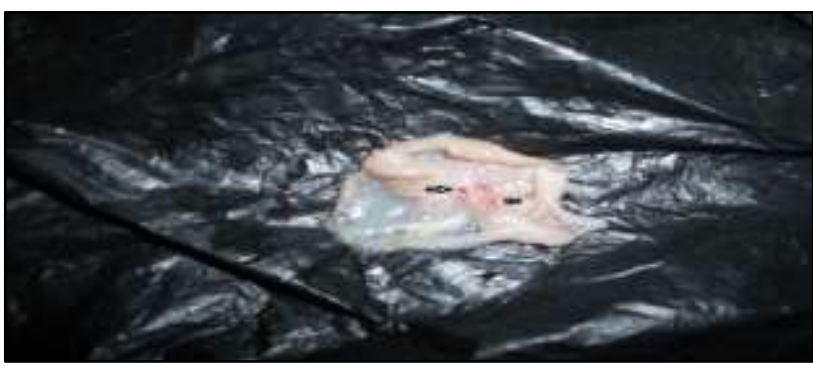

Figure 10: Gastric mucosa of rat pre-treated with enalapril $10 \mathrm{mg} / \mathrm{kg} / \mathrm{day}$ for 4 weeks duration before induction of ulcer by stress showing a decrease in the sizes of ulcers and in the severity of inflammation with a decrease in the incidence of ulceration to become $33 \%$.

Effect of losartan and enalapril on gastric mucosa and on the levels of gastric mucosal PGE2, SOD, CAT and $N O$ in stress- induced gastric ulcer in male albino rats

The pre-treatment of experimental animals with $3 \mathrm{mg} / \mathrm{kg} /$ day losartan and $10 \mathrm{mg} / \mathrm{kg} /$ day enalapril i.p for 4 weeks duration before induction of ulcer by stress, led to significant increase $(\mathrm{P}<0.05)$ in mucosal PGE2 level from $119 \pm 3.58$ to $181 \pm 4.74$ and to $165 \pm 4.96$ respectively, and in gastric mucosal SOD activity from $1.38 \pm 0.02$ to $1.94 \pm 0.02$ and $1.84 \pm 0.02$ respectively, also, increase occurred in NO level from $85 \pm 2.88$ to $145 \pm 2.89 \&$ $139 \pm 2.88$ respectively all compared to stress ulcer group (Figures 1, 2 and 4).

On the other hand, only losartan led to a significant increase $(\mathrm{P}<0.05)$ in the gastric mucosal activity of CAT from $3.14 \pm 0.03$ to $3.48 \pm 0.02$ but enalapril led to insignificant changes in this enzyme activity compared to stress control group (Figure 3). Macroscopically, pretreatment with losartan or enalapril for 4 weeks before induction of ulcer by stress produced decrease in the size of ulcer and in severity of inflammation with decrease in the incidence of ulceration to become $33 \%$ compared to stress ulcer group (Table 1 and Figure 9 and 10).

\section{Histopathological findings}

Light microscopic picture of gastric tissues after i.p. administration of losartan $3 \mathrm{mg} / \mathrm{kg} /$ day and enalapril 10 $\mathrm{mg} / \mathrm{kg} /$ day for 4 weeks

In the control group, light microscopic examination of gastric tissues showed normal gastric biopsy with intact mucosal surface and no significant inflammatory cell infiltration or edema. Light microscopic examination of gastric tissues after administration of losartan and enalapril also showed normal gastric biopsy with an intact mucosal surface (Microphotographs 11, 12 and 13).

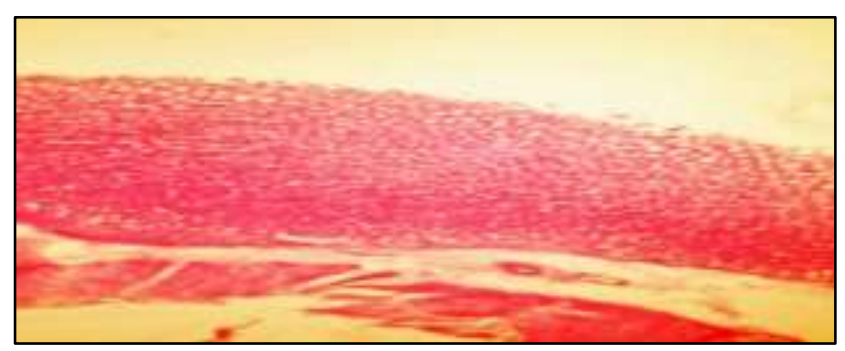

Figure 11: Microphotograph gastric biopsy from a rat in control group shows intact mucosal surface $H$ and $E$ $\mathbf{x} 40$.

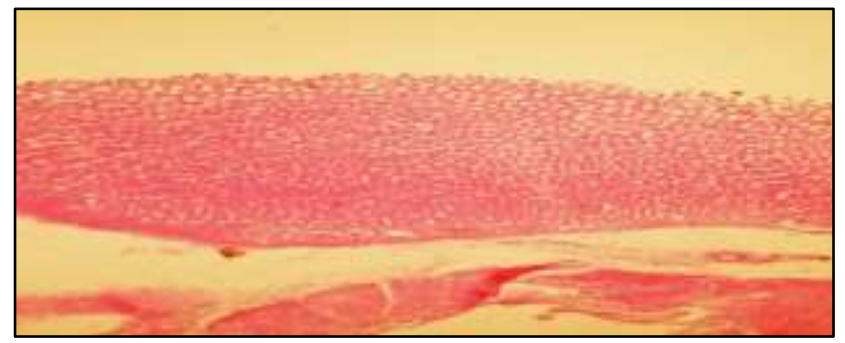

Figure 12: Microphotograph gastric biopsy from a rat treated with losartan in a dose of $3 \mathrm{mg} / \mathrm{kg}$ for 4 weeks duration showing intact mucosal surface $H$ and $E$ x40.

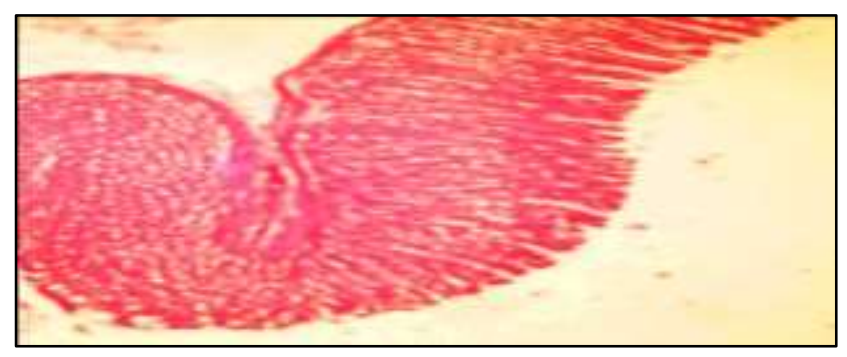

Figure 13: Microphotograph gastric biopsy from a rat treated with enalapril in a dose of $10 \mathrm{mg} / \mathrm{kg}$ for 4 weeks duration showing intact mucosal surface $H$ and E x40.

Light microscopic picture of gastric tissues pre-treated with losartan $3 \mathrm{mg} / \mathrm{kg} /$ day and enalapril $10 \mathrm{mg} / \mathrm{kg} /$ day for 4 weeks duration in stress-induced gastric tissues: 
Light microscopic examination of gastric tissues after induction of ulcer by stress showed epithelial damage, marked congestion and leucocytes infiltration of submucosa (Microphotograph D). Comparing the effect of losartan and enalapril on the histopathological changes in gastric tissue, it was found that the pretreatment with losartan and enalapril was showing superficial gastric epithelial erosion with no edema and no leucocytes infiltration of the submucosal layer (Microphotographs 14, 15 and 16).

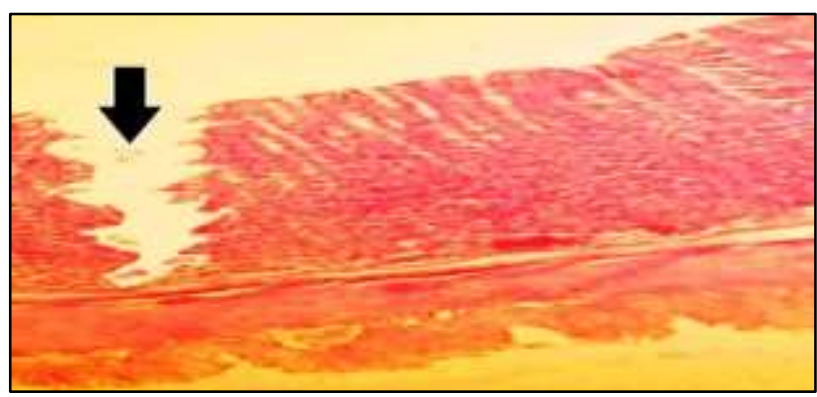

Figure14: Microphotograph gastric biopsy from a rat with stress-induced ulcer showing epithelial damage, necrotic damage of mid and lower mucosa, congestion of submucosa with leucocytic infiltration $H$ and $E$ $\mathbf{x 2 0 0 .}$.

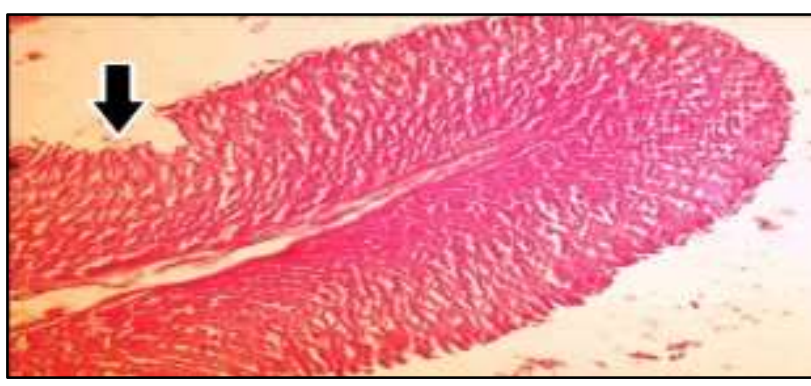

Figure 15: Microphotograph gastric biopsy from rat pre-treated with losartan in a dose of $3 \mathrm{mg} / \mathrm{kg} / \mathrm{day}$ for 4 weeks duration before induction of ulcer by stress showing superficial gastric epithelial erosion $\mathbf{H}$ and $\mathbf{E}$ x40.

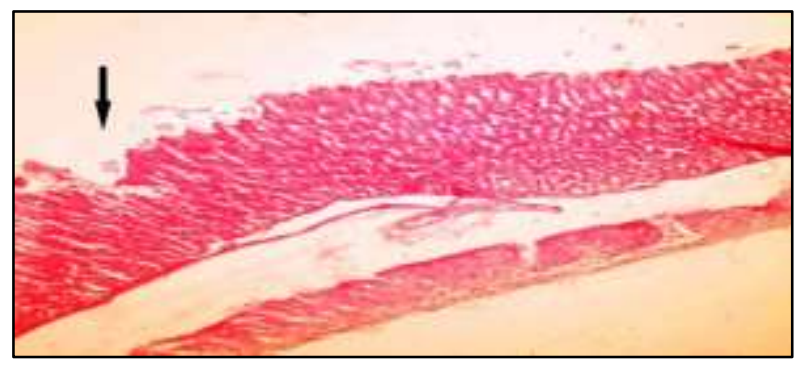

Figure 16: Microphotograph gastric biopsy from rat pre-treated with enalapril in a dose of $10 \mathrm{mg} / \mathrm{kg} / \mathrm{day}$ for 4 weeks duration before induction of ulcer by stress showing superficial gastric mucosal erosion. $\mathbf{H}$ and $\mathbf{E} \times 100$.

\section{DISCUSSION}

ANG II, the most active factor in RAS, is a well-known oxidative stress inducer. It increases the generation of superoxide anion, hydrogen peroxide, and hydroxyl radicals by activating the NADPH oxidase enzyme. ${ }^{18}$ Also, ANG II activates inflammatory cascades with increased production of the pro-inflammatory cytokine, tumor necrosis factor- $\alpha$ which is responsible for further gastric mucosal injury. ${ }^{4}$

The present work was constructed to detect the effect of losartan and enalapril, as RAS inhibitors, on gastric mucosa in the stress-induced gastric ulcer.

Our results demonstrated that exposure of experimental animals to stress by water immersion method produced gastric ulcer which was proved by macroscopic and microscopic pictures. In addition, the stress produced a reduction in mucosal PGE2 and NO concentration associated with a reduction in mucosal SOD and CAT activities. These findings are consistent with previous reports are done on stress ulcer in many studies. ${ }^{4,19,20}$

In general speaking, stress induces gastric mucosal lesions by complex psychological factors including a decrease in the release of protective factors like PGE2, antioxidant enzymes, bicarbonate, and mucus with an increase in the aggressive factors like acid. ${ }^{21}$ Stress leads to activation of hypothalamic pituitary adrenal cortex axis, decrease blood flow to the mucosa by vasoconstriction, stomach mast cell degranulation with histamine production, change in gastric motility and emptying rate and increases free radical generation resulting in increased lipid peroxidation. $^{22,23}$ Both clinical and preclinical studies have shown that psychological stress enhances helicobacter pylori infection and colonization of the stomach and this is facilitated in part through glucocorticoids. ${ }^{24}$

In the present work, we found that pre-treatment with losartan and enalapril for 4 weeks elicited a protective effect against gastric ulcer induced by stress and a significant decrease in the incidence of ulceration with no difference between losartan and enalapril. In the same context, the histopathological examination of gastric tissue revealed that losartan and enalapril were effective in reducing the deep gastric ulcer to superficial erosion.

This result supported the previous studies done on stressinduced gastric ulcers by Morsy et al and Seo et al where ulcers were ameliorated by the use of losartan and enalapril to shallow erosions and congestion, also this result was in harmony with similar studies done by Nakagiri et al 12 and Fouad et al who evaluated the effects of pre-treatment of losartan, candesartan and valsartan on ischemia/reperfusion- induced gastric ulcer and the effect of telmisartan on indomethacin-induced gastric ulceration in rats respectively, where the ulcers 

$\underset{27}{\text { were ameliorated to superficial gastric mucosal lesions. }}{ }^{25-}$

Moreover, the present study revealed that there is a significant increase in mucosal PGE2, SOD, and NO levels, compared to ulcer group with no significant difference between losartan and enalapril.

Prostaglandins play a pivotal role in the ulcer healing process by improving gastric mucin synthesis, triggering mucosal cell proliferation and promoting angiogenesis which regulates gastric mucosal integrity. ${ }^{28}$ Swartz et al proved that captopril increased PGE2 level in a human study, also, Molina-Molina et al revealed that losartan increased the level of PGE2 by increase its production. $^{29,30}$

Any imbalance in the activity of various antioxidant enzymes like CAT, SOD, and glutathione peroxidase leads to faulty disposal of free radicals and its accumulation. ${ }^{31}$ Antioxidants seemed to have a protective role in gastric ulcers and carcinomas. ${ }^{9}$ Our results were in harmony with those obtained by Chandran et al who stated that enalapril and captopril have the ability to enhance SOD activity. ${ }^{32}$ Khaper and Singal and Ivanov et al have also similar results, where they proved that losartan increased catalase and SOD activity and decrease lipid peroxidation level. ${ }^{33,34}$

Administration of enalapril for 4 weeks in our study caused an insignificant rise in CAT activity compared to control ulcer group. This result was in agreement with the results of a study by De Cavanagh et al who revealed that SOD and glutathione peroxidase activities are increased by enalapril and captopril while CAT activity was not affected. $^{35}$

Endogenous NO has a role in the protection of gastric mucosa by the maintenance of mucosal blood flow, reduction of leukocyte endothelial cell rolling and adherence and stimulation of gastric mucus synthesis and secretion. ${ }^{36}$ It also increases PGE2 biosynthesis through a cGMP-independent pathway in the stomach after damage. ${ }^{37}$ Our result was consistent with that obtained by Boveris et al and Morsy et al. ${ }^{38,39}$ In addition, a study by Donmez et al revealed that both losartan and enalapril produced a significant increase in NO and glutathione levels after 9 weeks of treatment. ${ }^{40}$

Losartan, as one of the selective ARBs, was proved effective in enhancement the generation of antioxidant activity. This effect is related to the ability of its metabolite EXP3179 to prevent the activation of nuclear factor- $\kappa \mathrm{B}$ signaling pathway which promotes the transcription of NADPH oxidase, tumor necrosis factor- $\alpha$ $(\mathrm{TNF}-\alpha)$ and inducible (NOS) genes. ${ }^{41}$ Other mechanisms independent of AT1R blockade; losartan acts as a partial agonist at the nuclear peroxisome proliferator-activated receptor- $\gamma(\operatorname{PPAR} \gamma){ }^{42}$ Activation of this receptor induces catalase gene expression and inhibits nuclear factor- $\kappa \mathrm{B}$, thus, combating oxidative stress and down regulating most of the pro-inflammatory responses. ${ }^{43}$

Enalapril, as an ACE inhibitor, increases the activities of the antioxidant enzymes could be due to their direct effect on enzyme synthesis or activity and inhibition of ANG II synthesis. Low molecular weight peptides which modify SOD activity were isolated from human plasma, where enalapril is considered as one of these peptides. ${ }^{35}$ In addition, enalapril inhibits the phosphorylation of protein kinase R-like endoplasmic reticulum kinase (PERK) and eukaryotic initiation factor 2 (eIF $2 \alpha$ ) and decrease the expression of activating transcription factor 3 (ATF3) which leads to enhancing the antioxidant activity. ${ }^{44}$

Stress stimulates the RAS by enhancing ANG II formation which leads to vasoconstriction and generation of free radicals causing a gastric ulcer. So, treatment with losartan or enalapril ameliorates the stress-induced ulceration of the gastric mucosa.

\section{CONCLUSION}

In conclusion, the results of our study showed that losartan and enalapril protected gastric mucosa from stress induced gastric ulceration by increase mucosal PGE2 and NO levels and SOD activity with no significant difference between losartan and enalapril, while losartan had an additional stimulating effect on CAT activity.

\section{ACKNOWLEDGEMENTS}

Authors would like to thanks to Dr. Noha EL. Daba lecture of Pathology, Sohag University for her help in the completion of this project.

Funding: No funding sources

Conflict of interest: None declared

Ethical approval: The study was approved by the Institutional Ethics Committee

\section{REFERENCES}

1. Wang Y, Richter J, Dempsey D. Trends and outcomes of hospitalizations for peptic ulcer disease in the United States, 1993 to 2006. Ann Surg. 2010;251:51-8.

2. Jain K, Shah A, Bariwal J. Recent advances in proton pump inhibitors and management of acid-peptic disorders. Bioorg Med Chem. 2007;15:1181-205.

3. Parente L, Parretti M. Advances in the pathophysiology of constitutive and inducible cyclooxygenases. Biochem Pharmacol. 2003;65:153-9.

4. Bregonzio C, Armando I, Ando H. Antiinflammatory effects of angiotensin II AT1 receptor antagonism prevents stress-induced gastric injury. Am J Physiol Gastrointest Liver Physiol. 2003;285(2):414-23. 
5. Dongcheng M, Xueguang Z, Wei X. The pathogenic role of endogenous angiotensin II in stress ulcer in obstructive jaundice rats. Chin Med J. 1998;111:309-12.

6. Carl-McGrath S, Grantzdorffer I, Lendeckel U. Angiotensin II-generating enzymes, angiotensinconverting enzyme (ACE) and mast cell chymase (CMA1), in gastric inflammation may be regulated by $\mathrm{H}$. pylori and associated cytokines. Pathology. 2009;41:419-27.

7. Heinemann A, Sattler V, Jocic M. Effect of angiotensin II and telmisartan, an angiotensin I receptor antagonist, on gastric mucosal blood flow. Aliment Pharmacol Ther. 1999;13:347-55.

8. Touyz R. Reactive oxygen species and angiotensin II signaling in vascular cells: implications in cardiovascular disease. Brazilian J Med Biological Research. 2004;37(8):1263-73.

9. Tandon R, Khanna H, Dorababu M. Oxidative stress and antioxidants status in peptic ulcer and gastric carcinoma. Indian J Physiol Pharmacol. 2004;48:115-8.

10. Shiotani A, Sakakibara T, Yamanaka Y. Upper gastrointestinal ulcer in Japanese patients taking lowdose aspirin. J Gastroenterol. 2009;4:126-31.

11. Ueyama T, Saika M, Koreeda C, Senba E. Water immersion restraint stress induces expression of immediate early genes in gastrointestinal tract of rats. Am J Physiol. 1998;275(2pt1):287-95.

12. Nakagiri A, Sunamoto M, Murakami M. Angiotensin AT1 receptor blockers suppress ischemia/reperfusion induced gastric injury in rats. Inflammopharmacol. 2007;15(4):171-4.

13. Baluchnejadmojarad T, Roghani M, Imani A. Protective effect of enalapril on vascular reactivity of the rat aorta. Vasc Pharmacol. 2004;40:301-7.

14. Fernández N, Alonso S, Valera I, Vigo A. Mannosecontaining molecular patterns are strong inducers of cyclooxygenase-2 expression and prostaglandin E2 production in human macrophages. J Immunol. 2005;174:8154-62.

15. Nishikimi M, Roa A, Yagi K. The occurrence of superoxide anion in the reaction of reduced phenazine methosulfate and molecular oxygen. Biochem Biophys Res Commun. 1972;64(2):849-54.

16. Aebi H. Catalase in vitro. Methods Enzymol. 1984;105:121-6.

17. Montgomery H, Dymock J. The determination of nitrite in water. Analyst. 1961;86:414-6.

18. Cai H, Griendling K, Harrison D. The vascular NAD (P) $\mathrm{H}$ oxidases as therapeutic targets in cardiovascular diseases. Trends Pharmacol Sci. 2003;24(9):471-8.

19. Ajaikumar K, Asheef M, Babu B. The inhibition of gastric mucosal injury by Punicagranatum L. (pomegranate) methanolic extract. J Ethnopharmacol. 2005;96(1):171-6.

20. Tanaka A, Hatazawa R, Takahira Y. Preconditioning stress prevents cold restraint stress-induced gastric lesions in rats: roles of COX-1, COX-2, and PLA2. Dig Dis Sci. 2007;52(2):478-87.

21. Suleyman H, Albayrak A, Bilic M, Cadirci E. Different mechanisms in formation and prevention of indomethacin-induced gastric ulcers. Inflammation. 2010;33(4):224-34.

22. Bhatia V, Tandon R. Stress and the gastrointestinal tract. J Gastroenterol Hepatol. 2005;20(3):332-9.

23. Andrade T, Graeff F. Effect of electrolytic and neurotoxic lesions of the median raphe nucleus on anxiety and stress. Pharmacol Biochem Behav. 2001;70(1):1-14

24. Guo G, Jia K, Shi Y, Liu X, Liu K, Qi W. Psychological stress enhances the colonization of the stomach by helicobacter pylori in the BALB/c mouse. Stress. 2009;12(6):478-85.

25. Morsy M, Heeba G, Abdelwahab S. Protective effects of nebivolol against cold restraint stressinduced gastric ulcer in rats: Role of $\mathrm{NO}, \mathrm{HO}-1$, and COX-1, 2. Nitric Oxide. 2012;27(2):117-22.

26. Seo P, Kim N, Kim J. Comparison of indomethacin, diclofenac and aspirin-induced gastric damage according to age in rats. Gut Liver. 2012;6(2):210-7.

27. Fouad A, Al-Sultan A, Yacoubi M. Ameliorative effects of telmisartan in diabetic rats with indomethacin-induced gastric ulceration. Eur $\mathbf{J}$ Pharmacol. 2010;637(1):162-70.

28. Brzozowski T, Konturek P, Konturek S. Role of prostaglandins in gastroprotection and gastric adaptation. J Physiol Pharmacol. 2005;5:33-55.

29. Swartz S, Williams G, Hollenberg N. Captoprilinduced Changes in Prostaglandin Production relationship to vascular response in normal man. $\mathbf{J}$ Clin Invest. 1980;65(6):1257-64.

30. Molina-Molina M, Serrano-Mollar A, Bulbena O. Losartan attenuates bleomycin induced lung fibrosis by increasing prostaglandin E2 synthesis. Thorax. 2006;61(7):604-10.

31. Fridovich I. Biological effects of superoxide radical. Arch Biochem Biophy. 1986;247:1-11.

32. Chandran G, Sirajudeen K, Yusoff N, Swamy M. Effect of the antihypertensive drug enalapril on oxidative stress markers and antioxidant enzymes in the kidney of spontaneously hypertensive rats. Oxid Med Cell Longev. 2014;2014:608512.

33. Khaper N, Singal P. Modulation of oxidative stress by a selective inhibition of angiotensin II type 1 receptors in MI rats. J Am Coll Cardiol. 2001;37(5):1461-6.

34. Ivanov M, Mihailović-Stanojević N, Milanović J. Losartan improved antioxidant defense, renal function and structure of postischemic hypertensive kidney PLoS one. 2014;9(5):1-7.

35. De Cavanagh E, Inserra F, Ferder L. Superoxide dismutase and glutathione peroxidase activities are increased by enalapril and captopril in mouse liver. FEBS Lett. 1995;361(1):22-4.

36. Calatayud S, Sanz M, Canet A. Mechanisms of gastroprotection by transdermal nitroglycerin in the rat. Br J Pharmacol. 1999;127:1111-8. 
37. Mollace V, Muscoli C, Masini E. Modulation of prostaglandin biosynthesis by nitric oxide and nitric oxide donors. Pharmacol Rev. 2005;57(2):217-52.

38. Boveris A, D'Amico G, Lores-Arnaiz S. Enalapril increases mitochondrial nitric oxide synthase activity in heart and liver. Antioxid Redox Signal. 2003;5(6):691-7.

39. Morsy M, Ashour O, Amin E. Gastroprotective effects of telmisartan on experimentally induced gastric ulcers in rats. Pharmazie. 2009;64(9):590-4.

40. Donmez G, Derici U, Erbas D. The effects of losartan and enalapril therapies on the levels of nitric oxide, malondialdehyde, and glutathione in patients with essential hypertension. J Physiol. 2002;52(5):435-40.

41. Yu X, Zhang D, Jia L, Qi J. Inhibition of NF- $\mathrm{B}$ activity in the hypothalamic paraventricular nucleus attenuates hypertension and cardiac hypertrophy by modulating cytokines and attenuating oxidative stress. Toxicol Appl Pharmacol. 2015;284(3):315-22.

42. Koh E, Yoon S, Lee S. Losartan protects the liver against ischemia/reperfusion injury through PPAR- $\gamma$ activation and receptor for advanced glycation endproducts down-regulation. $\mathrm{Br} \mathrm{J}$ Pharmacol. 2013;169(6):1404-16.

43. Nakamura T, Keep R, Hua Y. Oxidative DNA injury after experimental intracerebral hemorrhage. Brain Res. 2005;1039(1):30-6.

44. Zhou Y, Zhao L, Zhang Z, Lu X. Protective Effect of enalapril against methionine-enriched diet-induced hypertension: role of endoplasmic reticulum and oxidative stress. Biomed Res Int. 2015;724876.

Cite this article as: Ahmed SA, Abdel-Rahim MH, Abdel-latif HM. The role of losartan and enalapril in the protection against stress-induced gastric mucosal ulceration in rats. Int $\mathrm{J}$ Basic Clin Pharmacol 2016;5:1034-42. 